\title{
THE EFFECT OF MODERATE EXERCISE ON MONOCYTE CHEMO-ATTRACTANT PROTEIN-1 IN ATHEROGENIC OVARIECTOMIZED RATS
}

\author{
Mohammed Abd EL hamed.M. El sayed, Akmal Ahmed. H. Diab, Shereen El Araby Bedair, and Heba Atef El \\ sayed*
}

Physiology Department, Faculty of Medicine, Zagazig University, Zagazig, Sharkia, Egypt

\section{ABSTRACT}

Background: Cardiovascular disease (CVD) is one of the leading causes of death worldwide and is more prevalent in post-menopausal women. Monocyte chemo-attractant protein-1(MCP-1) is a chemokine that attracts monocytes/macrophages to sites of inflammation and play a role in development of atherosclerosis. Objective: This study aimed to explore the effects of ovariectomy $(\mathrm{Ovx})$ as a model of menopause on the serum level of MCP-1 in high fat diet induced atherogenesis and clarify the modulatory effects of moderate exercises on the serum level of MCP-1 in this model. Animals and methods: 96 female albino rats divided equally into 4 groups, each is subdivided equally into 2subgroups subgroup (Ia): non ovx ,sedentary, fed standard diet for 10 weeks, subgroup (Ib): non ovx ,sedentary, fed high fat diet for 10 weeks. Subgroup (IIa) ovx sedentary, fed standard diet for 10 weeks subgroup (IIb): ovx, sedentary fed high fat diet for 10 weeks. Subgroup (IIIa): non ovx ,exercised and fed standard diet for 10 weeks. subgroup (IIIb) non ovx ,exercised and fed high fat diet for 10 weeks. Subgroup (IVa): ovx ,exercised and fed standard diet for 10 weeks. subgroup (IVb) ovx ,exercised and fed high fat diet for 10 weeks. Results: in ovx obese sedentary rats, there was a significant $(\mathrm{p}<0.001)$ increase in MCP-1,Lipid profile, Atherogenic indices, Platelets activation percentage, Total leucocytic counts, Differential monocyte counts, and Interleukin 8 and aortic thickness versus lean subgroup. Swimming exercise showed significant $(p<0.001)$ reductions in the above parameters, associated with significant increase in the serum HDL level in ovx obese exercised subgroup versus ovx obese sedentary subgroup. Conclusions: MCP-1 level increased in obesity and menopause leading to development of atherosclerosis and these changes could be reversed by adaptive moderate exercises.

Keywords: MCP-1, Ovariectomy, Obesity, Atherosclerosis, Swimming exercise. Corresponding Author: Heba Atef El sayed Tel: 01008930926

\section{INTRODUCTION}

$\mathbf{M}$ enopause is permanent cessation of menstruation has social, reproductive, physical and psychological impact on woman health due to withdrawal of estrogen and subsequent disturbances [1]. Postmenopausal women are at greater risk for cardiovascular disease (CVD) than premenopausal so decrease of estrogen due to natural or surgical menopause increases the risk of developing coronary atherosclerosis ${ }^{[2]}$. Atherosclerosis is a systemic vascular inflammatory disease that proceed to coronary artery disease, myocardial infarction, and stroke which are the main causes of death ${ }^{[3]}$. It has been predicted that by the year 2050 one billion women worldwide will be postmenopausal [4], so preventive or therapeutic intervention important to limit coronary artery disease and its associated health risks [5]. MCP-1 is a chemokine produced by inflammatory endothelial cells, platelets. Also adipocytes are important source of MCP-1 ${ }^{[6]}$. It helps initiation and development of atherosclerotic lesion ${ }^{[7]}$. It was found that it was associated with carotid intima-media thickness, which reflects generalized atherosclerosis ${ }^{[8]}$. MCP-1 also plays a vital role as chemo-attractant, growth regulators of osteoblast and osteoclast activity and involved in the physiological bone remodeling process ${ }^{[9]}$. It has been reported that serum MCP-1 level increased in ovarictomy and during menopausal transition ${ }^{[10]}$, suggesting that it is indicator of hormonal changes ${ }^{[11]}$. Some studies reported that MCP1 plays a vital role in inflammatory processes and metabolic disturbances in high fat diet ${ }^{[12]}$. Others reported no effect of MCP-1 on metabolic parameters ${ }^{[13,14]}$. It has been reported that MCP-1 correlated with markers of the metabolic syndrome including: obesity, insulin resistance, Type 2 diabetes, hypertension ${ }^{[15]}$. Moreover, it has been 
reported that poor exercise is a greater contributor to the risk of cardiovascular death ${ }^{[16]}$. Fitness modulation improves risk of $10 \%$ of CVD mortality ${ }^{[17]}$. Regarding the effect of exercise on serum level of MCP-1, the previous studies have shown controversial results as Some studies reported that exercise decreased serum levels of the chemokines and MCP-1 in metabolic syndrome patients ${ }^{[18]}$, while others founded that exercise increased serum level of MCP-1 in patients at risk for coronary artery disease ${ }^{[19]}$. Therefore, this study was designed to explore and clarify the modulatory effects of moderate exercise on the serum level of MCP-1 in the menopausal model of atherogenesis.

\section{ANIMALS AND METHODS}

A total number of 96 healthy adult female albino rats $8-10$ weeks old weighting 180 $200 \mathrm{~g}$, were obtained from the faculty of veterinary medicine Zagazig University. Animals were provided free access to food and water and were left for 48 hours prior to the beginning of the experiments for adaptation to laboratory conditions. Rats were randomized and divided into Group I $(n=24)$ : Non- ovariectomized, sedentary group, subdivided equally into Subgroup (I a): were fed standard laboratory chow for 10 weeks and Subgroup (I b): were fed Atherogenic diet for 10 week. Group II ( $n=24)$ : bilaterally Ovx and subdivided into Subgroup (IIa): were fed standard laboratory chow for 10 week and Subgroup (II b): were fed atherogenic diet for 10 week. Group III $(n=24)$ : Nonovariectomized, exercised group) also subdivided into Subgroup IIIa: fed standard diet, performed swimming for 10 weeks, Subgroup IIIb: fed atherogenic diet, performed swimming exercise for 10 weeks. Group IV (Ovariectomized, exercised group) bilateral ovx, subdivided into Subgroup IVa fed standard diet and swimming exercise for 10 weeks, Subgroup IVb fed atherogenic diet, swimming exercise for 10 weeks. Rats in normal fed subgroups received standard chow composed of $3.89 \mathrm{Kcal} / \mathrm{gm}$ (Casein $33.11 \%$, Cystine $0.30 \%$, Starch $25.21 \%$ Dextrose
$25.21 \%$, Cellulose 5.00\%, Soybean oil 5.00\%, Minerals $5.00 \%$, Vitamins $1.00 \%$, Colin $0.17 \%$, and Lard $0 \%$ ) while the rats fed atherogenic diet composed of Maize $(8.9 \mathrm{~kg})$, Soya bean meal $(3.74 \mathrm{~kg})$, Oat dry grain $(17.5$ $\mathrm{kg}$ ), Wheat bran $(5 \mathrm{~kg})$, Rice bran $(12.5 \mathrm{~kg})$, Egg shell $(1 \mathrm{~kg})$, Bone meal $(0.5 \mathrm{~kg})$, Common salt $(0.13 \mathrm{~kg})$, Fish meal $(0.5 \mathrm{~kg})$, Sunflower oil $(0.30 \mathrm{~kg})$ and Cholesterol $(0.10 \mathrm{~kg})^{[20]}$.

\section{Ovariectomy:}

Ovariectomy was performed by mid-ventral method which was technically easier ${ }^{[21]}$. Rats were fasted overnight, and then they were anaesthetized intra peritoneal with thiopental sodium $40 \mathrm{mg} / \mathrm{kg}$ bodyweight. After anesthesia, the animals were put in the dorsal recumbence. The mid ventral area was shaved and cleaned by alcohol, Then Skin incision was done and Skin was separated from underlying muscle. Incision was made on the linea alba followed by peritoneum. Uterus was exteriorized by gentle traction which extends posterior- medially to form $\mathrm{V}$ shape. Then ovaries were exposed from fat and exteriorized and removed. The uterine horns were returned back to the abdominal cavity. The peritoneum and linea alba were closed with simple interrupted pattern using 3/0 chromic catgut and skin was closed with cross mattress using $1 / 0$ silk ${ }^{[22,23]}$. Finally, the closed incision covered with sterilized gauze and rats were observed until the recovery from anesthesia. Ampicillin sodium was given to rats $(25 \mathrm{mg} / \mathrm{kg}$, IM) for 3 days to guard against post-operative infections. Suture was removed on 8th day postoperative. The exercise was initiated one week after recovery from ovariectomy ${ }^{[24]}$.

\section{Exercise regimen:}

Swimming was selected as our exercise regimen as it is less stressful ${ }^{[24]}$. Sedentary rats remain in a tank filled with water to a depth of $5 \mathrm{~cm}$, when the exercised rats practiced swimming in plastic tanks with 90 $\mathrm{cm}$ diameter, $50 \mathrm{~cm}$ height and filled with water to a depth of $35 \mathrm{~cm}$. The water temperature was maintained at $32 \pm 1^{\circ} \mathrm{C}$, warm water was added if the water temperature 
dropped below $30^{\circ} \mathrm{C}$. Rats were continuously observed during swimming to prevent drowning. At the end of each daily swimming session, each rat was dried with a towel until their fur was completely dried before being returned to their cages ${ }^{[25]}$. Rats were trained to the swimming exercise during the first week. Initially, rats swam for $15 \mathrm{~min}$, increasing of additional $15 \mathrm{~min}$ daily, until a swimming period of one hour was attained at the end of the first week. The exercise was done for 5 days per week between $1 \mathrm{pm}$ and 3 $\mathrm{pm}$ and this was maintained for 10 weeks ${ }^{[26]}$.

\section{Measurement of BMI :}

At the start and at the end of the experimental period before sacrificing, rats were weighted in all groups by the digital balance, and their lengths were taken from nose to anus by graduated metal ruler. Body mass index (BMI) was calculated using the following equation: BMI $(\mathrm{gm} / \mathrm{cm} 2)=$ body weight $(\mathrm{gm}) /$ length $2(\mathrm{~cm} 2)^{[27]}$.

\section{Blood Sampling:}

General anesthesia was performed using thiopental sodium $50 \mathrm{mg} / \mathrm{kg}$ body weight intra peritoneal. Then rats were sacrificed by decapitation and blood sample was collected into two tubes: In one tube, the blood was allowed to clot and Serum was separated by centrifugation of blood at $3000 \mathrm{rpm}$ for 15 minutes. The supernatant serum was pipetted off using fine tipped automatic pipettes and stored frozen at $-20{ }^{\circ} \mathrm{C}$ until assayed for MCP1, IL-8, lipid Profile (TC, TG, HDL, LDL) and atherogenic index. The other tube (EDTA tube), that contain EDTA for anticoagulation. Plasma was separated by centrifugation of blood for $15 \mathrm{~min}$. The supernatant plasma was immediately used for assessment of platelet activation, total and differential leukocyte counts.

\section{Platelets aggregation:}

Determination of platelet aggregation was done according to Marcus et al. ${ }^{[28]}$ using DiaMed kits. Platelets were stimulated to aggregate by ADP. These aggregations were determined by optical density in turbo optical instrument (540) dual channel aggrego meter. Maximum aggregation is recorded as a percentage.

\section{Total \& Differential leukocytic counts:}

Total numbers of Leukocytes and its populations were quantitatively assessed using automatized blood cell counter ${ }^{[29]}$.

\section{Atherogenic index:}

It was calculated as follows [TC - (HDL-C)] / (HDL-C) ${ }^{[30]}$.

\section{Sampling of tissues:}

After collection of blood samples, the thoracic and abdominal aorta were dissected, cleaned from adventitia and immersed in a phosphate buffered formalin solution. Paraffin section were prepared and stained by haematoxylin $\&$ eosin for histological examination of aortic strips.

\section{Morphometric analysis:}

The thickness of tunica media were measured from photos of X 400 magnification using Digimizer 4.3.2.Image analysis software (Med Calc Software bvba, Belgium).Then the value of the thickness from each sample was finally statistically compared.

\section{Statistical Analysis:}

The data obtained in the present study were expressed as mean \pm SD for quantitative variables and statistically analyzed by using SPSS program (version 18 for windows) (SPSS Inc. Chicago, IL, USA). One way Analysis of Variance (ANOVA) was used to compare the results of all examined groups followed by LSD test to compare statistical differences between groups. $\mathrm{P}$ value $<0.05$ was considered statistically significant.

\section{RESULTS}

The results revealed non-significant increase in BMIs, serum cholesterol, T.G, LDL, MCP-1, IL8 level, atherogenic index, platelets activations, total leucocytic counts, differential monocyte counts, and aortic thickness in lean ovx sedentary subgroup versus its value in the lean non- ovx sedentary subgroup. Moreover, there was also nonsignificant decrease in the previous parameters in lean exercised versus its value in the lean sedentary subgroup. In addition, 
there was non-significant reduction in the previous mentioned parameters in lean ovx exercised subgroup when compared with lean ovx. sedentary subgroup. The results also showed significant increases in the previous mentioned parameters in the obese non-ovx sedentary subgroup associated with nondetectable changes in the aortic thickness when compared with lean non-ovx sedentary subgroup. However, the results showed significant increases in the above parameters in obese ovx sedentary rats when compared with non-ovx obese sedentary subgroup. On the other hands, regarding the effect of exercise, the existing results showed significant reductions in the mentioned parameters, associated with significant increase in the serum HDL level in non-ovx obese exercised subgroup when compared with non-ovx obese sedentary subgroup. Furthermore, following moderate trained exercise, obese ovx. subgroup showed significant reductions in the same mentioned parameters as well as significant increase in serum HDL level when compared with ovx obese sedentary subgroup. In addition, the present study also demonstrated a statistically significant positive correlations between serum levels of MCP-1 and BMI, cholesterol, T.G, LDL, atherogenic index, platelets activation, TLC, DMC, IL-8, aortic thickness and statistically significant negative correlations between serum levels of MCP-1 and HDL in ovx. sedentary group. Also, statistically significant positive correlations were found between serum levels of MCP1 and these parameters in ovx. exercise group.

Table (1) Show: comparison of all studied parameters in non-ovx and ovx sedentary studied groups.

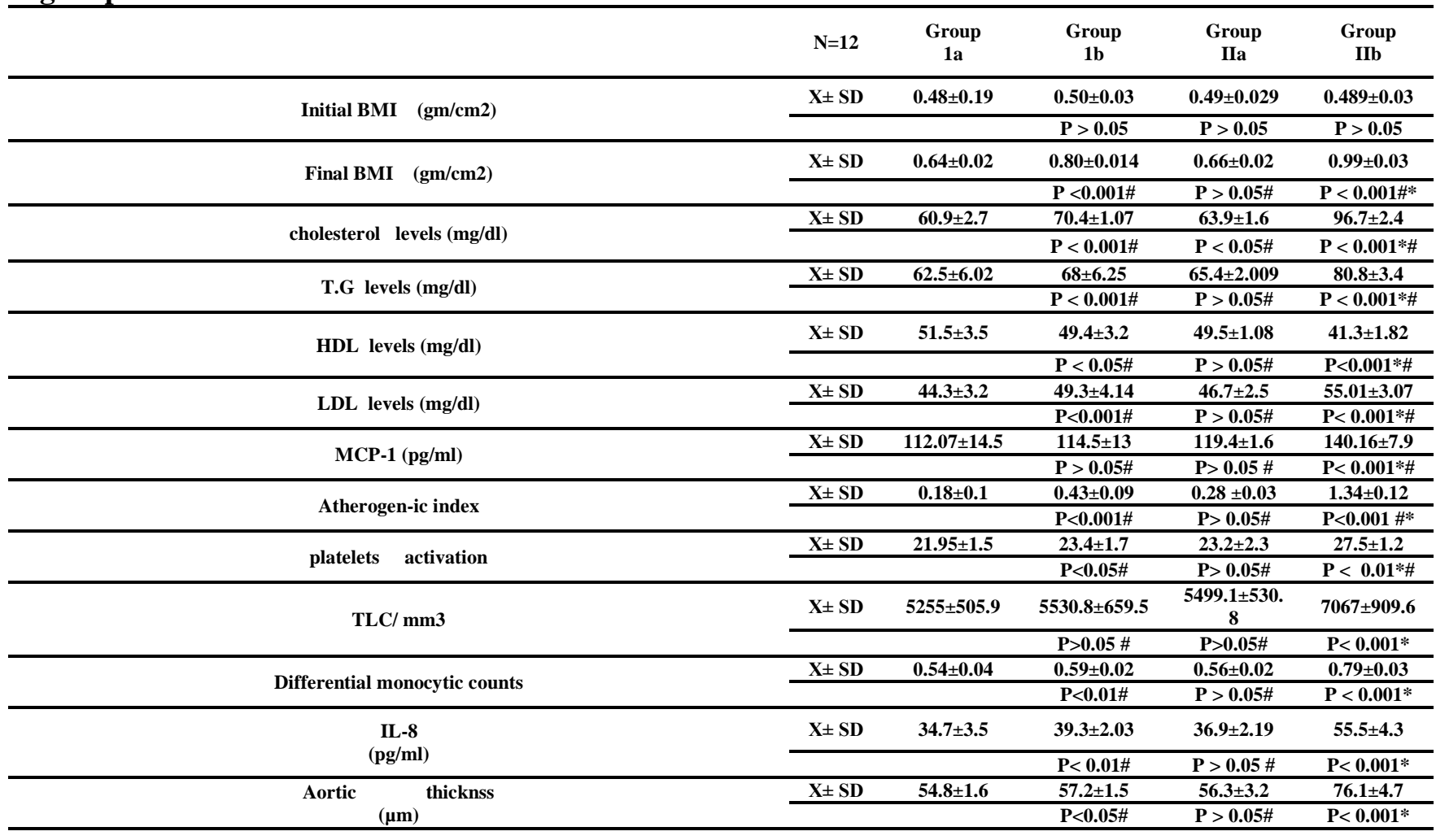


Table (2) Show: comparison of all studied parameters in non-ovx and ovx exercised studied groups.

\begin{tabular}{|c|c|c|c|c|}
\hline $\begin{array}{c}\text { Group } \\
\text { IIb }\end{array}$ & Group & $\begin{array}{c}\text { Group } \\
\text { III b }\end{array}$ & $\begin{array}{c}\text { Group } \\
\text { IV a }\end{array}$ & $\begin{array}{c}\text { Group } \\
\text { IV b }\end{array}$ \\
\hline Initial BMI（gm/cm2) & $0.50 \pm 0.02$ & $0.49 \pm 0.03$ & $0.50 \pm 0.028$ & $0.49 \pm 0.03$ \\
\hline \multirow{2}{*}{ Final BMI $\quad(\mathrm{gm} / \mathrm{cm} 2)$} & $0.63 \pm 0.13$ & $0.70 \pm 0.02$ & $0.65 \pm 0.09$ & $0.82 \pm 0.014$ \\
\hline & $P>0.05 \#$ & $\mathrm{P}<0.001 *$ & $P>0.05 \#$ & $P>0.05 * \$$ \\
\hline cholesterol levels (mg/dl) & $59.16 \pm 4.1$ & $63.9 \pm 1.6$ & $61.6 \pm 4.1$ & $72.9 \pm 2.1$ \\
\hline \multirow{2}{*}{ T.G levels (mg/dl) } & $61.4 \pm 1.6$ & $63.19 \pm 1.8$ & $62.5 \pm 1.7$ & $69.6 \pm 2.9$ \\
\hline & $\mathrm{P}>0.05 \#$ & $\mathrm{P}<0.01 *$ & $\mathbf{P}>0.05 \#$ & $\mathrm{P}>0.05 * \$$ \\
\hline \multirow{2}{*}{ HDL levels (mg/dl) } & $51.5 \pm 3.26$ & $53 \pm 2.2$ & $51.1 \pm 2.26$ & $47.5 \pm 1.87$ \\
\hline & $P>0.05 \#$ & $\mathrm{P}<0.01 *$ & $P>0.05 \#$ & $\mathrm{P}>0.05 * \$$ \\
\hline \multirow{2}{*}{ LDL levels (mg/dl) } & $43.5 \pm 3.1$ & $45.3 \pm 1.07$ & $45 \pm 3.7$ & $50.08 \pm 2.4$ \\
\hline & $P>0.05 \#$ & $\mathrm{P}<0.01 *$ & $P>0.05 \#$ & $\mathrm{P}>0.05^{*} \$$ \\
\hline MCP-1 (pg/ml) & $111.12 \pm 12.3$ & $112.4 \pm 6.3$ & $113.6 \pm 8.6$ & $115.04 \pm 10.1$ \\
\hline \multirow{2}{*}{ Atherogen-ic index } & $0.14 \pm 0.08$ & $0.19 \pm 0.07$ & $0.20 \pm 0.07$ & $0.53 \pm 0.09$ \\
\hline & $\mathrm{P}>0.05 \#$ & $\mathrm{P}<0.001 \# *$ & $\mathrm{P}>0.05 \#$ & $P<0.001 * \$$ \\
\hline \multirow{2}{*}{ platelets activation } & $21.94 \pm 1.3$ & $21.9 \pm 1.54$ & $22.03 \pm 1.4$ & $25.3 \pm 1.9$ \\
\hline & $\mathrm{P}>0.05 \#$ & $\mathrm{P}<0.05 * \#$ & $\mathrm{P}>0.05 \#$ & $\mathrm{P}<0.01 * \$$ \\
\hline \multirow{2}{*}{$\mathrm{TLC} / \mathbf{m m} 3$} & $5253.5 \pm 484.09$ & $5257.9 \pm 256.15$ & $5398.6 \pm 525.06$ & $5545.4 \pm 320.4$ \\
\hline & P>0.05\# & $\mathbf{P}>0.05 *$ & $\mathrm{P}>0.05 \#$ & $\mathrm{P}>0.05 *$ \\
\hline \multirow{2}{*}{$\begin{array}{c}\text { Differential monocytic } \\
\text { counts }\end{array}$} & $0.52 \pm 0.007$ & $0.48 \pm 0.03$ & $0.54 \pm 0.017$ & $0.60 \pm 0.02$ \\
\hline & $P>0.05 \#$ & $\mathrm{P}<0.001 *$ & $P>0.05 \#$ & $\mathrm{P}>0.05^{*} \$$ \\
\hline \multirow{2}{*}{$\begin{array}{c}\text { IL-8 } \\
(\mathbf{p g} / \mathrm{ml})\end{array}$} & $33.16 \pm 2.8$ & $34.7 \pm 3.2$ & $34.7 \pm 1.2$ & $40.4 \pm 4.6$ \\
\hline & $P>0.05 \#$ & $\mathrm{P}<0.001 *$ & $P>0.05 \#$ & $\mathrm{P}>0.05 * \$$ \\
\hline \multirow{2}{*}{ Aortic ${ }_{(\mu \mathrm{m})}^{\text {thicknss }}$} & $53.9 \pm 2.02$ & $54.84 \pm 1.5$ & $54.8 \pm 1.8$ & $60.4 \pm 4.3$ \\
\hline & $P>0.05 \#$ & $\mathrm{P}<0.05^{*}$ & $P>0.05 \#$ & $\mathrm{P}<0.05 * \$$ \\
\hline
\end{tabular}

\# versus I a. * versus I b. \$ versus II b. TLC: total leucocytic counts

Table (3): Correlation between MCP-1 level and other parameters in HFD ovariectomised subgroups.

\begin{tabular}{|c|c|c|c|c|}
\hline & \multicolumn{2}{|c|}{$\begin{array}{c}\text { Ovx sedentary } \\
\text { subgroup } \\
\text { (II b) } \\
\end{array}$} & \multicolumn{2}{|c|}{$\begin{array}{l}\text { Ovx exercised } \\
\text { subgroup } \\
\text { (IV b) } \\
\end{array}$} \\
\hline & $\mathbf{R}$ & $\mathbf{P}$ & $\mathbf{r}$ & $\mathbf{P}$ \\
\hline BMI & $0.665^{*}$ & 0.018 & $0.639 *$ & 0.025 \\
\hline Cholesterol & $0.602 *$ & 0.038 & $0.603 *$ & 0.038 \\
\hline T.G & $0.632 *$ & 0.027 & $0.594 *$ & 0.042 \\
\hline HDL & $-0.642 *$ & 0.025 & $-0.582 *$ & 0.047 \\
\hline LDL & $0.678 *$ & 0.015 & $0.610 *$ & 0.035 \\
\hline Atherogenic index & $0.770 * *$ & 0.003 & $0.773 * *$ & 0.003 \\
\hline Platelets activations & $0.644^{*}$ & 0.024 & $0.677^{*}$ & 0.016 \\
\hline $\begin{array}{c}\text { Total } \\
\text { leukocytic counts }\end{array}$ & $0.586^{*}$ & 0.045 & $0.652 *$ & 0.022 \\
\hline Differential monocytic counts & $0.768 * *$ & 0.004 & $0.776 * *$ & 0.003 \\
\hline Interleukin 8 & $.734 * *$ & 0.007 & $0.859 * *$ & 0.000 \\
\hline Aortic thickness & $0.731 * *$ & 0.007 & $0.763 * *$ & 0.004 \\
\hline
\end{tabular}




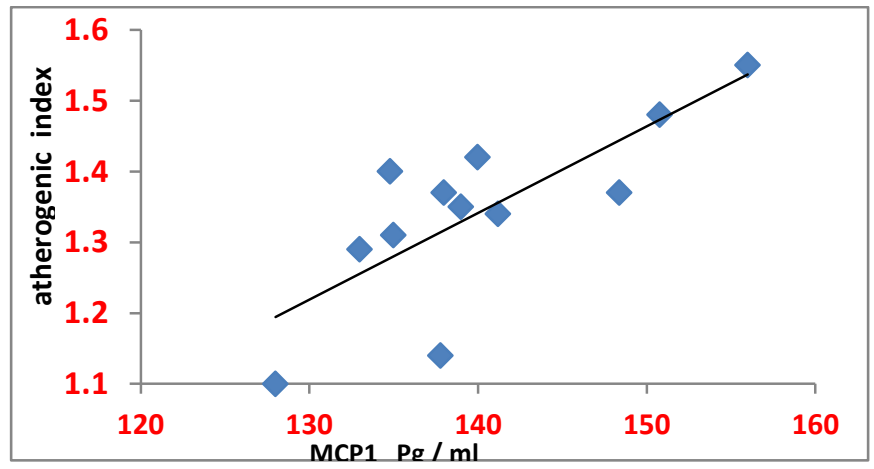

Fig (1): Correlation between MCP-1 and atherogenic index in obese ovx subgroup;

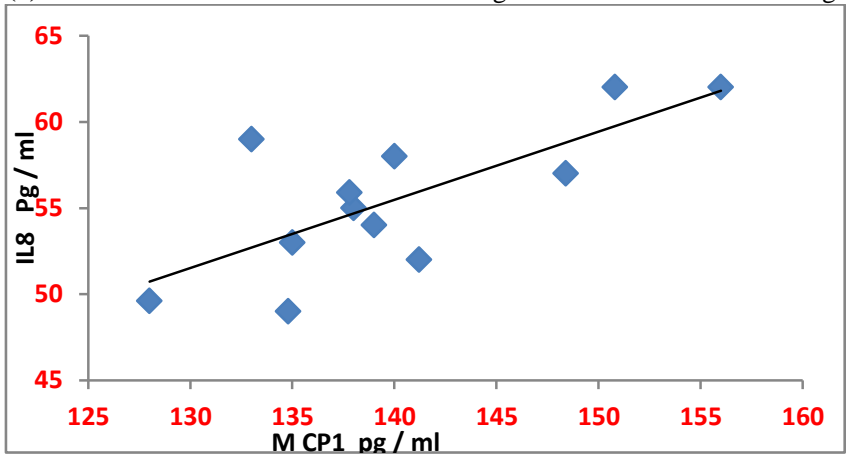

Fig (2): Correlation between MCP-1 and il8 in obese ovx subgroup.

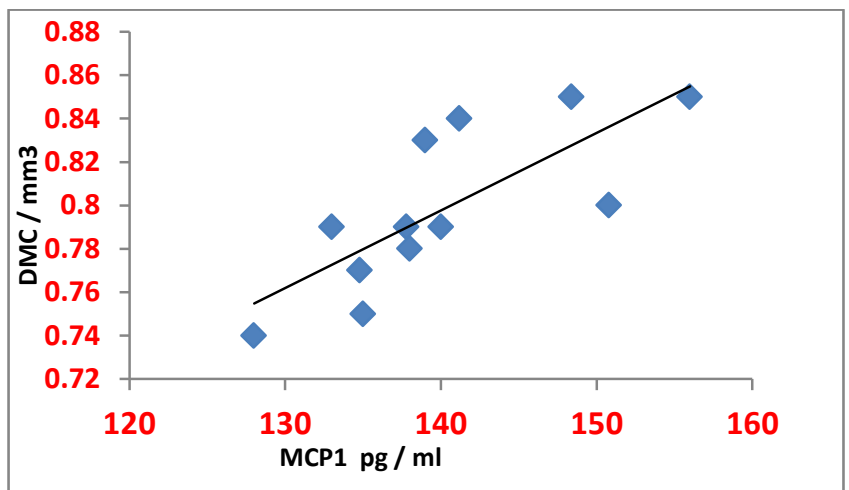

Fig (3): Correlation between MCP-1 and DMC in obese ovx subgroup.

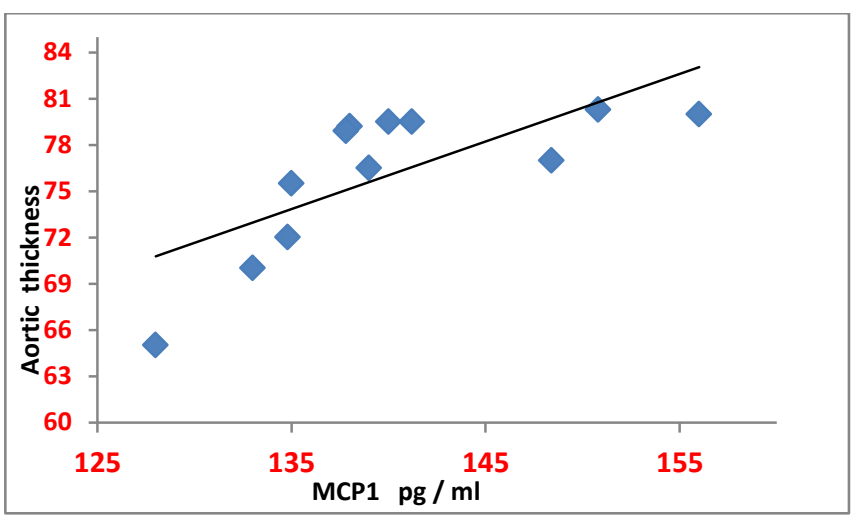

Fig (4): Correlation between MCP-1 and aortic thickness obese ovx subgroup. 


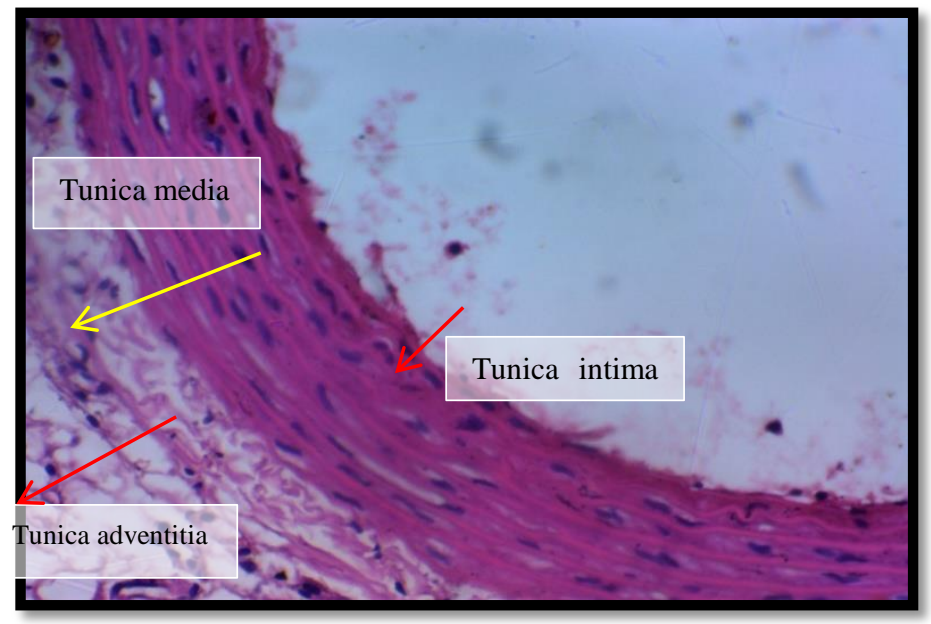

Slide (1): A photomicrograph of aortic artery histopathology in Group Ia (lean rat) H \& E stain x 400 magnification.

Showing the normal structure of the tunica intima, tunica media and tunica adventitia. The intimal surface was smooth and regular and was composed of a continuous layer of flat endothelial cells with normal thickness, tunica media characterized by regularly arranged smooth muscle fibers in addition to normal thickness of tunica media.

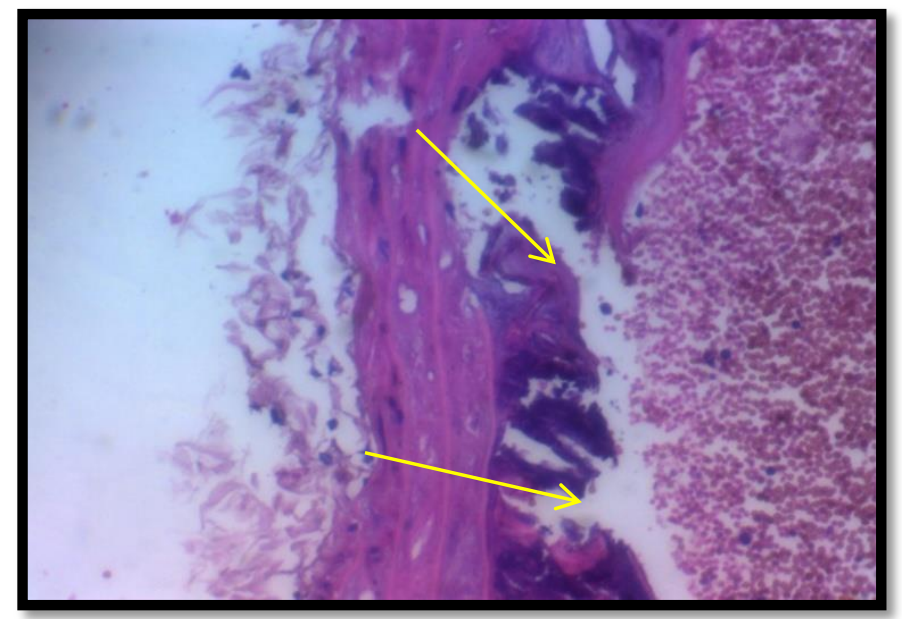

Slide (2): Another photomicrograph of aortic artery histopathology in Group IIb (ovariectomized with high fat diet (H \& E stain x 400 magnification).

Showing ruptured atheromatous plaqueand focal atrophy in media. 


\section{DISCUSSION}

Hormonal changes in menopause such as low plasma estrogen level and increased Luteinizing Hormone (LH) and Follicle Stimulating Hormone (FSH) levels are responsible for dyslipidemia that causes CVD and associated complications ${ }^{[31 \& 32]}$. Activation of platelets and leukocytes contributes to progression of atherosclerosis ${ }^{[33]}$.So thrombosis activated early in the development of cardiovascular diseases ${ }^{[34]}$.The results revealed non-significant increase in BMIs, serum cholesterol, T.G, LDL, MCP-1, IL8 level, atherogenic index, platelets activations, total leucocytic counts, differential monocyte counts, and aortic thickness in lean ovx. sedentary subgroup versus its value in the lean non- ovx sedentary subgroup. In addition, there was non-

Significant reduction in the previous parameters in lean ovx. exercised subgroup when compared with lean ovx. sedentary subgroup. The results also showed significant increases in the above parameters in the obese non-ovx sedentary subgroup when compared with lean non-ovx sedentary subgroup. As regards the ovariectomy and obesity, our results demonstrated significant increases in the above parameters in obese ovx sedentary rats when compared with non-ovx obese sedentary subgroup. On the other hands, regarding the effect of exercise, the existing results showed significant reductions in the above mentioned parameters, associated with significant increase in the serum HDL level in non-ovx obese exercised subgroup when compared with nonovx obese sedentary subgroup. Furthermore, following moderate trained exercise, obese ovx. subgroup induced significant reductions in the above mentioned parameters as well as significant increase in serum HDL level when compared with ovx obese sedentary subgroup. These results indicate that obesity increases BMI and lipid profile. It induced low grade inflammation, followed by recruitment of monocytes toward inflammations and increasing pro-inflammatory cytokines (MCP-
1, IL-8), monocytes counts, and proliferation of haemopioetic stem cells increasing total leucocytic counts. The model of menopause and post-menopausal women are at risk of obesity due to lack of exercise and lower basal metabolic rate that leads to abnormal redistribution of body fats results and visceral adiposity ${ }^{[35]}$. Obesity and decreased estrogen in menopause are associated with disturbed metabolic changes such as insulin resistance, that leads to development of type II diabetes mellitus and hyperlipidemia together with CHD leads to metabolic syndrome. These results are consistent with several studies that observed increased BMI and obesity in old menopausal women and marked increase of weight after hysterectomy with bilateral oophorectomy in women transitioning into menopause ${ }^{[36-38]}$. This may be due to estrogen and progesterone withdrawal causing disturbance in homeostasis e.g. decreases in insulin sensitivity and leptin secretion and changes in lipid metabolism, leading to a decreased in energy expenditure. Together with physical inactivity and consumption of a high fat diet, these factors significantly contribute to obesity and risk of CHD in postmenopausal women ${ }^{[39]}$. However, others found no effect of bilateral ovariectomy on BMI ${ }^{[40]}$. In addition, Tan, et al. [41] performed cross-sectional studies and founded no association between BMI and menopausal symptoms. The controversial findings may be due to different ages and menopausal status of the studied samples ${ }^{[42]}$. As regards the effect of exercise on increased BMI in menopause, the current results in agreement with the North American Menopause Society ${ }^{[43]}$ and Yeh et al. [44] who reported that exercise can help menopausal women to improve weight, BMI and body fat measures. The present results about lipid profile, comes in agreement with several studies that reported significantly increased TC, T.G, and LDL-C associated with decreased HDL levels especially in postmenopausal women with metabolic syndrome. ${ }^{[45,46] .}$ Also another study reported 
that TC,T.G, HDL-C, and LDL-C were significantly increased in postmenopausal women than in premenopausal women ${ }^{[47]}$.This changes in lipid profile may be explained as estrogen deficiency increase the activity of hormone sensitive lipase resulting in increased free fatty acid level and accumulation of abdominal fat which is a risk factor for cardiovascular disorders and insulin resistance. Also the decrease in LDL receptor synthesis with consequent increased in LDL level as a result of decrease estrogen stimulatory effects on synthesis of LDL receptor after menopause ${ }^{[48]}$.As regards the effect of exercise on lipid profile, the existing results in agreement with other studies that showed combination of aerobic exercise and resistance training ,decreased total cholesterol, triglycerides and LDL-C, increased HDL-C and improved glycemic control and insulin resistance. ${ }^{[49,50]} \mathrm{On}$ the contrary, Antoninus et al. ${ }^{[51]}$ founded significant reduction in HDL-C after interval exercise training. However, no significant change in HDL in continuous training. This may be referred to the type and interval of exercise training programs. In the present study, the results detected increase in MCP-1 level in obese ovx subgroup compared to obese nonovx subgroup which is consistent with the studies that reported increased MCP-1 level in obese ovx mice in post-menopausal obese women than premenopausal ${ }^{[11]}$. This may be due to loss of estrogen anti-inflammatory effects associated with increased level of cytokines, that leads to impaired vascular function and impaired metabolism. On the other hands, Park et al. ${ }^{[52]}$ founded that MCP-1 level not significantly different between nonobese and obese women and it was associated with menopausal status irrespective of obesity. Regarding the effect of moderate swimming exercise, current results show significant reduction of $\mathrm{MCP}-1$,consistent with these results, studies demonstrated that high-fat diet caused a significant increase in MCP-1 level, which was decreased after exercise due to decreased its expression ${ }^{[53,54]}$. In addition, other studies reported that high intensity interval training reduced MCP-1 levels due to more reduction in oxidative stress ${ }^{[55,56]}$. On the contrary, a study detected up regulation in MCP-1in skeletal muscle cells, associated with increased its serum level after moderate exercise ${ }^{[57]}$. Moreover, short bouts of strenuous exercise produce significant increase in MCP-1 in healthy persons ${ }^{[58]}$. These controversies may be contributed to the difference in exercise program e.g. moderate exercise in the present work versus strenuous exercise in the other studies. In addition, may be referred to the difference in duration of exercise e.g. $60 \mathrm{~min}$ in the present work versus $8-10 \mathrm{~min}$ in the previous studies. The current results showed significant increase in serum IL8 in both obese non-ovx and obese ovx subgroup. In concordance with the present finding several studies showed increased IL-8, and MCP1expression from the adipocytes. Their levels correlate with a higher BMI and this significant increase in IL-8 level persist for a long period after estrogen deficiency. ${ }^{[59,11,60]}$ In contradiction, Dorneles et al. ${ }^{[61]}$ demonstrated that high intensity interval exercise (HIIE) decreased IL- 8 in lean and obese individuals. Also, Thorbjorn et al. ${ }^{[62]}$ founded that exercise increased IL-8 expression in skeletal muscle but small release of IL- 8 from muscle not elevate plasma level of IL-8. Zwetsloot et al. ${ }^{[54]}$ Observed that after strenuous prolonged exercise IL- 8 increased. These data indicated that IL-8 level is affected by intensity of exercise. The present study detected significant increase in atherogenic index in both obese non-ovx and obese ovx subgroup versus lean subgroup, these results also comes in agreement with other several studies, As Pourfarzam, et al. ${ }^{[63]}$; Zhan et al. ${ }^{[64]}$; Gaojun Cai et al. ${ }^{[65]}$; Shen et al. ${ }^{[66]}$ demonstrated that atherogenic index associated with metabolic syndrome and it was higher in coronary heart diseases. Furthermore it was positively correlated with TC, TG and negatively correlated with HDL-C. In addition, 
Bakry et al. ${ }^{[67]}$ showed that atherogenic index used as a significant predictor of atherosclerosis and CVD. Regarding the effect of exercise on atherogenic index in the previously mentioned subgroups, the results are in consistent with the study done by Antoninus et al. ${ }^{[51]}$ who showed that continuous exercise training significantly decrease the atherogenic index of plasma as a method of decreasing cardiovascular risk in sedentary non-obese males. On the other hands, Ghorbanian B et al. ${ }^{[68]}$ founded that aerobic exercise training induced non-significant decrease AIP in post- menopausal women, and TG, LDL-c/HDL-c, and TC/HDL-c significantly decreased. The current study also revealed elevated levels of platelets activations after ovariectomy is in agreement with the study done by Lundberg et al. ${ }^{[69]}$ and Singla A. et al. ${ }^{[70]}$ who reported that platelets of postmenopausal women were more reactive to aggregate than of premenopausal suggesting increased incidence of athero-thrombotic events in postmenopausal women. This may be because platelets contain the estrogen receptor $\beta, 17 \beta$-estradiol has inhibitory effects on platelet aggregation in vitro and this inhibition is lost in postmenopausal women. ${ }^{[71]}$ As regards the effect of exercise on platelet activation in menopause, the current results in consistent with the study done by Heber et al. ${ }^{[72]}$ who reported that exercise decreased platelet reactivity in old women. Regarding effects of obesity and oophorectomy on WBCs, the present results are in concordance with Jung et al. ${ }^{[73]}$ who reported that total and differential WBC counts increased with age and with BMI. All subtypes of WBCs were positively associated with serum triglyceride levels and negatively associated with serum HDL cholesterol, that are characters of atherosclerosis. Also, Karino et al. ${ }^{[7]}$ reported that increased total and differential WBC counts associated with higher risk of CHD in elder Japanese-American men. As regards the effect of exercise on WBC count in menopause, existing data in agreement with the study done by Neil et al. ${ }^{[75]}$ who reported that aerobic exercise training decreased total $\mathrm{WBC}$ and neutrophil counts, in obese post-menopausal women. Also Uba Chupel et al. ${ }^{[76]}$ showed that Strength training exercises decreased leukocyte and lymphocyte counts in older women. On the other hand, Dorneles et al. ${ }^{[77]}$ founded that high intensity interval exercise increased leukocytes, monocytes and lymphocytes counts in obese group. These differences may be due to the short duration and different type of exercises. Regarding effects of obesity and menopause on monocyte counts, the existing results in consistent with several studies. Zernecke et al. [78] detected that Apo-lipoprotein mice with disturbed lipid profile, develop a model of atherosclerosis with leukocytosis, especially monocytosis. Apo E deficiency disturbs cholesterol efflux, increases membrane cholesterol content and the surface expression of the IL-3 receptor that stimulates proliferation of hematopoietic stem cell in the bone marrow and the spleen leading to monocytosis [79]. Konstantin et al. ${ }^{[80]}$ founded association between high levels of atherogenic Lipoproteins and increased pro inflammatory monocytes in atherosclerosis. Mohammed Shamim et al. ${ }^{[81]}$ explained how disturbed lipid profile leads to monocytosis. Hyperlipidemia alters bone marrow production of monocyte precursors and mature monocytes and promotes accumulation of lipid droplets in monocyte subsets; inducing pro inflammatory chemotaxis of monocytes and increasing tissue damage during atherogenesis. As regards the effect of exercise on monocytosis, the present results are inconsistent with Timmerman et al. ${ }^{[82]}$ who founded that exercise training decrease monocyte counts in a physically inactive population. Koichi Node et al. ${ }^{[83]}$ reported that exercise significantly decreased Leukocytes, monocytes, and neutrophil counts. Aerobic exercise training can affect some inflammatory processes and increased aerobic capacity may be anti-inflammatory and have cardiovascular protective effects in obese women. On the other 
hand, Mendham et al. ${ }^{[84]}$ reported significant leukocytosis, monocytosis and lymphocytosis immediately after a moderate exercise in obese men, independent of exercise intensity and maybe explained by chemotactic factors or increased sympathetic discharge ${ }^{[85]}$. The increased aortic thickness that detected in the ovx obese subgroup in the current work is consistent with Amano et al. ${ }^{[86]}$ who reported that MCP-1 stimulates macrophage division and accelerates atherosclerotic changes with increase in aortic thickness with consequence increase incidence of cardiovascular disease. The effect of exercise on the aortic thickness, our current data in consistent with the study that reported aortic thickness correlates with carotid intima-media thickness, this indicates a systemic diseases. The patients with increased intima-media thickness of the carotid have risk of cardiovascular mortality ${ }^{[87]}$.

\section{CONCLUSIONS}

The present study demonstrated increases in serumMCP-1 ofpost-menopausal atherosclerotic obese experimental model. This increase was positively correlated with pro-inflammatory and thrombotic markers and associated with histopathological alterations of the aortic artery. These changes were significantly improved after moderate trained exercise.

\section{RECOMMENDATIONS}

Post-menopausal women especially with bad hypercholesterolemic dietary regimen appear to be prone to have atherosclerosis and CVD complications. So it is advisable to correct faulty dietary habits and follow moderate trained exercise program to protect against cardiovascular insults.

\section{REFERENCES}

1- Dosi R, Bhatt N, Shah P, Patell R. (2014): Cardiovascular disease and menopause. J Clin Diagn Res; 8(2):62-64.

2- Hodis HN, Mack WJ (2014): Hormone replacement therapy and the association with coronary heart disease and overall mortality: clinical application of the timing hypothesis. Biol. ; 142:68-75.
3-Barrett Connor E (2013): Menopause, atherosclerosis, and coronary artery disease. Curr. Opin. Pharmacol. ; 13(2): 186-91.

4-Barton M, Meyer MR. (2009): Postmenopausal hypertension: mechanisms and therapy. Hypertension ; 54(1): 11-8.

5-Clarkson TB, Meléndez GC, Appt SE (2013): timing hypothesis for postmenopausal hormone therapy: its origin, current status, and future. Menopause. 20 (3):342-53.

6- Huber J, Kiefer FW, Zeyda M, Ludvik B, Silberhumer GR, Prager et al. (2008): CC chemokine and $\mathrm{CC}$ chemokine receptor profiles in visceral and subcutaneous adipose tissue are altered in human obesity. J Clin Endocrinol Metab.; 93(8): 3215-21.

7-Mohanty P, Aljada A, Ghanim H, Hofmeyer D, Tripathy D, Syed T et al. (2004). Evidence for a potent anti inflammatory effect of rosiglitazone. J Clin Endocrinol Metab; 89: 2728-2735.

8-Brenner D. Labreuche J. Touboul PJ. Schmidt-Petersen K. Poirier O. Perret C. et al (2006): Cytokine poly- morphisms associated with carotid intima-media thickness in stroke patients ;37:1691-1696.

9-Jawed A. and Nicola C. (2017): CCL2/Monocyte Chemo-attractant Protein 1 and Parathyroid Hormone Action on Bone Department of Basic Science and Craniofacial Biology, Endocrinol.; https: //doi.org/ 10. 3389/fendo.00049.

10-Kim YY, Kim SH, Oh S, Sul OK, Lee HY, et al. (2010): Increased Fat due to Estrogen Deficiency Induces Bone Loss by Elevating Monocyte Chemo-attractant Protein (MCP-1) Production. Mol. Cell; 29: 277-282.

11-Tani A, Yasui T, Matsui S, Kato T, Kunimi K, et al. (2013): Different circulating levels of monocyte chemo-attractant protein-1 and interleukin-8 during the menopausal transition. Cytokine ;62: 86-90.

12-Weisberg SP, Hunter D, Huber R, Lemieux J, Slaymaker S, Vaddi $K$ et al. (2006): CCR2 modulates inflammatory and metabolic effects of high-fat feeding. J Clin Invest ; 116: 115-124.

13-Chow FY, Nikolic-Paterson DJ, Ma FY, Ozols E, Rollins BJ, Tesch GH. (2007): Monocyte chemo-attractant protein-1-induced tissue inflammation is critical for the development of 
renal injury but not type 2 diabetes in obese $\mathrm{db} / \mathrm{db}$ mice. Diabetologia ; 50: 471-480.

14-Kirk EA, Sagawa ZK, McDonald TO, O'Brien KD, Heinecke JW (2008): Monocyte chemo-attractant protein deficiency fails to restrain macrophage infiltration into adipose tissue [corrected]. Diabetes;57: 1254-121.

15-Simeoni E.,Hoffmann M.,Winkelmann B. R.,Ruiz J., Fleury S., et al. (2004): Association between the A-2518G polymorphism in the monocyte chemo-attractant protein-1 gene and insulin resistance and Type 2 diabetes mellitus. Diabetologia;47:1574-1580.

16-Blair SN. (2009): Physical inactivity: the biggest public health problem of the $21 \mathrm{st}$ century. Br J Sport Med;43:1-2.

17-Berry JD, Willis B, Gupta S, et al.(2013): Lifetime risks for cardiovascular disease mortality by cardiorespiratory fitness levels measured at age 45-, 55-, and 65-years in men: the Cooper Center Longitudinal Study. J Am Coll Cardiol.

18-Marius Trøseid, Knut T Lappegård, et al.: (2004): Exercise reduces plasma levels of the chemokines MCP-1 and IL- 8 in subjects with the metabolic syndrome. 349-355.

19-Becker D, Seul M, Lindemann S. (2005): Strenuous physical exercise induces monocyte chemo-attractant protein-1 release in patients with coronary artery disease Journal;4:1-6ISSN1611-2156.

20- Saso, K Kitamura , A Yasoshima , H O Iwasaki, K Takashima, K Doi, Morita (1992): Rapid Induction of Atherosclerosis Histol Histopathol ; 7(3), 315-320.7

21- Sankar, P. Veena, P. Suresh Kumar, R.V. et al., (2014): Ovariectomy in forty rats. J. Anim. Res.; 48(5): 516.517.

22-Lasota A, Danowska-Klonowska D. (2004): Experimental osteoporosis-different methods of ovariectomy in female white rats. Rocz Akad Med Bialymst; 49(Suppl1): 129-31.

23-Parhizkar S, Ibrahim R, Latiff LA. (2008): Incision choice in laparatomy: a comparison of two incision techniques in ovariectomy of rats. World Apple Sci J.; 4:537-40.

24-Souza SB, Flues K, Paulini J, et al. (2007): Role of Exercise Training in Cardiovascular Autonomic Dysfunction and Mortalityin Diabetic Ovariectomized rats. Hypertension; 50(4): 78691.
25-Lee H, Kim H, Lee JW, et al. (2006): Maternal swimming during pregnancy enhances shortterm memory and neurogenesis in the hippocampus of rat pups. Brain Dev; 28:147154.

26-Rocha R, Peraçoli JC, Volpato GT, et al., (2014): Effect of exercise on the maternal outcome in pregnancy of spontaneously hypertensive rats. Acta Cir Bras.; 29(9): 553-9.

27-Cicogna, VB NovelliFilho, ELB Novelli, et al.(2007): Anthropometrical parameters and markers of obesity in rats. Lab Anim; 41: 111.

28-Marcus AJ, Broekman MJ, Safier L. et al (1982): Formation of leukotrienes and other hydroxy acids during platelet-neutrophil interactions in vitro. Biochem Biophys Res Commun.;16; 109(1): 130-7.

29-Budds, O.C., E.S. Russell, and G.E. Abrams (1953): Effects of genetics and anesthesia upon granulocyte and a granulocyte levels in seven inbred mouse strains. Proc. Soc. Exp. Biol. Med; 84:176-178.

30-Li Yang; Yong-Hui Shi; Gang Hao; Wu Li and Guo-Wei Le (2008): Increasing Oxidative Stress with Progressive Hyperlipidemia in Human: Relation between Malondialdehyde and Atherogenic Index. J. Clin. Biochem. Nutr; 43: 154-158.

31-Deepthi, J. Naidu, and A. R. Narayan, (2012): "Relationship between estrogen and lipid profile status in postmenopausal women," International Journal of Applied Biology and Pharmaceutical Technology; 3, (3), 230-234.

32-Goliasch G, Wiesbauer F, Blessberger $\mathrm{H}$, et al. (2015): Premature myocardial infarction is strongly associated with increased levels of remnant cholesterol. J Clin Lipidol ; 9:801-6.

33-Libby P, Ridker PM, Hansson GK. (2011): Progress and challenges in translating the biology of atherosclerosis. Nature; 473(7347) :317-25. Epub 05/20. pmid: 21593864.

34-Ed Rainger G, Chimen M, Harrison MJ, Yates CM, Harrison P, Watson SP, et al. (2015): The role of platelets in the recruitment of leukocytes during vasculardisease.Platelets;26(6):507-20.Epub. pmid : 26 196409.

35-Tchernof,A.\&Despres,J.P.(2013): Pathophy siology of human visceral obesity: an update. Physiol. Rev. 93, 359-404. 
36-Laxmi Maru, Rajesh Verma, Monica Verma, Monica (2016): Correlation of body mass index and age of menopause in women attending medicine and gynaecology department of a tertiary care centre Department of Obstetrics and gynaecology, MGM Medical College, Indore, Madhya Pradesh, India International Journal of Research in Medical Sciences. Int. J.; Res. Med. Sci.

37-Carolyn J. Gibson, MPH, MS,1 Rebecca C. et al., (2013):Body Mass Index Following Natural Menopause and Hysterectomy with and without Bilateral Oophorectomy Int J Obes (Lond). Published in final edited form as: Int $\mathrm{J}$ Obes (Lond).; 37(6): 809-813.doi: 10.1038/ijo.164.

38-Sutton-Tyrrell K, Zhao X, Santoro N, et al., (2010) :Reproductive hormones and obesity: 9 years of observation from the Study of Women's Health Across the Nation. Am J Epidemiol ; 171(11):1203-13.

39-Viroj Boony aratana kornkit and Prangwan Pateetin, (2015): "The Role of Ovarian Sex Steroids in Metabolic Homeostasis, Obesity, and Postmenopausal Breast Cancer Molecula Mechanisms and Therapeutic Implications," Bio Med doi: $10.1155 / / 140196$.

40-Cooper R, Kuh D, Hardy R, Power C. (2007): Is there an association between hysterectomy and subsequent adiposity? Maturitas. 20;58 (3):296-307.

41-Tan MN, Kartal M, Guldal D(2014): The effect of physical activity and body mass index on menopausal symptoms in Turkish women: a cross-sectional study in primary care. BMC Women Health. Mar; 14(1): 38.

42-Moorman PG, Schildkraut JM, Iversen ES, Myers ER, Gradison M, Warren-White N, et al. (2009): A prospective study of weight gain after premenopausal hysterectomy. J Women Health Larchmt; 18(5): 699-708.

43-North American Menopause Society (NAMS) (2015): "Physical activity has greater impact on body composition in postmenopausal women "Science Daily;151019123445 .htm.

44-Yeh, M.-L \& Wang, P.-C \& Lin, J.-G \& Lin, I.-H \& Chen, H.-H. (2011): The effect of exercise on body composition in menopausal women: A systematic review and meta-analysis. Journal of Nursing and Healthcare Research; 7. $35-44$.
45-Zahra Jouyandeh, Farnaz Nayebzadeh, Mostafa Qorbani, and Mojgan Asadi (2013): Metabolic syndrome and menopause Jornal of Diabetes Metab Disord.; 12:1.

46-Shenoy and P. Vernekar, (2015): "Fasting lipid profile in pre-and post-menopausal women: a prospective study," International Journal of Scientific Study; 3 (9):116-119.

47-Bashu Dev Pardhe, Sumitra Ghimire, Jyotsna Shakya, et al., (2017): "Elevated Cardiovascular Risks among Postmenopausal Women: A Community Based Case Control Study from Nepal," Biochemistry Research International, Article ID34903, doi:10. 1155/ 3824903.

48-Kumar and C. Shah, (2012): "Oommen ER study of cardiovascular risk factors in pre and postmenopausal women," International Journal of Pharma Sciences and Research, 3 (12), 560570.

49-Roussel M, Garnier S, Lemoine S, Gaubert I, Charbonnier L, et al. (2009): Influence of a walking program on the metabolic risk profile of obese postmenopausal women. Menopause ; 16: 566-575.

50-Augusto Libardi C, Bonganha V, Soares Conceição M, et al. (2012): The periodized resistance training promotes similar changes in lipid profile in middle aged men and women. $\mathbf{J}$ Sports Med Phys Fitness; 52: 286-292.

51-Antoninus O Ezeukwu, Elias O Agwubike, and Patrick O Uadia (2015): Differential Effects of Continuous and Interval Exercise Training on the Atherogenic Index of Plasma in the Non-Obese Young Male Acta Cardiol Sin.; 31(4): 337-344.

52-Park KS, Ahn KJ, Kim BJ, Kim HJ, Yoo SM, Kim JY, Lee KH,et al., (2009): Circulating concentration MCP-1are associated with menopause status in Korean women. Clin Chim Acta; 403 (12): 926.

53-Jinho Ko and Kijin Kim (2013): Effects of exercise and diet composition on expression of MCP-1 and oxidative stress-related mRNA of adipose tissue in diet-induced obese mice Exercise. Nutrition. Biochem; 17(4):181188.

54-Zwetsloot, C. S. John, M. M. Lawrence, R. A. Battista, and R. A. Shanely, (2014): "Highintensity interval training induces a modest systemic inflammatory response in active, young 
men, "Journal of Inflammation Research, 7 (1) : 9-17.

55-Peake, S. J. Tan, J. F. Markworth, J. A. et al.,, (2014): "Metabolic and hormonal responses to isoenergetic high-intensity interval exercise and continuous moderate-intensity exercise," The American Journal of Physiology Endocrinology and Metabolism ; 307(7): E539E552.

56-Peter, M. Rehli, K. Singer, K. Renner-Sattler, and M.Kreutz, 2015 "Lactic acid delays the inflammatory response of human monocytes," Biochemical and Biophysical Research Communications, 457(3),412-418.

57-Peake, K. Suzuki, M. Hordern, G. Wilson, K. Nosaka, and J. S. Coombes, (2005): "Plasma cytokine changes in relation to exercise intensity and muscle damage," European Journal of Applied Physiology, 95 (5)-6. 514-521.

58-Amaryllis H. Van Craenenbroeck, Katrijn Van Ackeren, Vicky Y. Hoymans, (2014): et al., "Acute Exercise-Induced Response of Monocyte Subtypes in Chronic Heart and Renal Failure," Mediators of Inflammation; 216534, 11 pages doi:10.1155/2014/21653.

59-Andrei Mihai Malutan, Mihu Dan, Costin Nicolae, and Mihu Carmen(2014): Pro inflammatory and anti-inflammatory cytokine changes related to menopause; 13(3):162-168. doi: $10.5114 / \mathrm{pm} . .43818$.

60-Tani A, Toshiyuki Yasui, Sumika Matsui, Takeshi Kato, Naoko et al. (2014): Circulating levels of monocyte chemo-attractant protein-1 and interleukin-7 in women who have undergone bilateral salpingooophorectomy.Jour.Inflamm.Res.2014;7 $: 17$.

61-Dorneles GP, Haddad DO, FagundesVO, Vargas BK, Kloecker A, Romão PR, Peres (2016): A High intensity interval exercise decreases IL-8 and enhances the immunemodulatory cytokine interleukin-10 in lean and overweight-obese individuals. Cytokine. ;77:19.

62Thorbjorn.Akerstrom,AdamSteensberg,Pernil leKeller,CharlotteKeller,MilenaPenkowa,and Bente Klarlund Pedersen (2011): Exercise induces interleukin8 expression in human skeletal muscle. J. Physiol.1;589 (13):3407.

63-Pourfarzam M, Zadhoush F, Sadeghi $M$. (2016): The difference in correlation between insulin resistance index and chronic inflammation in type 2 diabetes with and without metabolic syndrome. Adv Biomed Res;5:153.

64-Zhan Y, Xu T, Tan X. (2016): Two parameters reflect lipid-driven inflammatory state in acute coronary syndrome: atherogenic index of plasma, neutrophil-lymphocyte ratio. BMC Cardio-vasc. Disord;16:96.

65-Gaojun Cai, MD, Ganwei Shi, MD, Sheliang Xue, PhD, and Wei Lu, MD(2017) :The atherogenic index of plasma is a strong and independent predictor for coronary artery disease in the Chinese Han population Medicine 96(37): e8058.

66-Shen S, Lu Y, Dang Y, et al. (2017): Effect of aerobic exercise on the atherogenic index of plasma in middle-aged Chinese men with various body weights. Int J Cardio;230:1-5.

67-Bakry OA, El Farargy SM, Ghanayem N, Soliman A (2015): Atherogenic index of plasma in non-obese women with androgenetic alopecia. Int J Dermatol.; 54(9):e339-44.

68-Ghorbanian B, Saberi Y. (2017): The Effect of a Ten-Week Aerobic Training on Atherogenic Indices, Lipid Profile, and Body Composition in Postmenopausal Women with Type II Diabetes, J Obstet Gynecol. Cancer Res.;2(2):e11958.

69-Lundberg Slingsby, M. Nyberg, J. Egelund, C. M. Mandrup, R Frikke-Schmidt, N. S. Kirkby, Y. Hellsten (2017): Aerobic exercise training lowers platelet reactivity and improves platelet sensitivity to prostacyclin in pre- and postmenopausal women. DOI: 10.1111/ jth.13866.

70-Singla A, Bliden KP, Jeong YH, et al., (2013): Platelet reactivity and thrombogenicity in postmenopausal women. Menopause; 20: 57-63.

71-Wu GJ, Lee JJ, Chou DS, Jayakumar T, Hsiao G, Chen WF, Sheu JR. (2010): Inhibitory signaling of 17 beta-estradiol in platelet activation: the pivotal role of cyclic AMP-mediated nitric oxide synthase activation. Eur J Pharmacol; 649: 140-9.

72-Heber S, Assinger A, Pokan R, Volf I. (2016): Correlation between cardiorespiratory fitness and platelet function in healthy women. Med Sci Sports Exerc ; 48: 1101-10.1613-1621.

73-Jung Hee Kim, 1 Soo LimKyong Soo Park, 1 Hak Chul Jang and Sung Hee Choi (2017): Total and differential WBC counts are related with coronary artery atherosclerosis and increase 
the risk for cardiovascular disease in Korean Journal List PLoS One;12(7):e0180332.

74-Karino S1, Willcox BJ2, Fong K3, Lo S4, Abbott R5, Masaki KH6Atherosclerosis. (2015): Total and differential white blood cell counts predict eight-year incident coronary heart disease in elderly Japanese-American men: the Honolulu Heart Program.;238(2):153-8.

75-Neil M. Johannsen ,Damon L. Swift, William D. Johnsonet al. (2012): Effect of Different Doses of Aerobic Exercise on Total White Blood Cell (WBC) and WBC Subfraction Number in Postmenopausal Women: Eur J Pharmacol; 649: $140-9$.

76-Uba Chupel, Matheus \& Direito, Fábio \& Furtado, Guilherme et al., (2017): Strength Training Decreases Inflammation and Increases Cognition and Physical Fitness in Older Women with Cognitive Impairment. Frontiers in Physiology. 8. 10.3389/fphys. 00377.

77-Dorneles GP, Haddad DO, FagundesVO, Vargas BK, Kloecker Aet al.(2016):A High intensity interval exercise decreases IL-8 and enhances the immune-modulatory cytokine interleukin-10 in lean and overweight-obese individuals. Cytokine. ;77:1-9.

78-Zernecke A, Bot I, Djalali-Talab Y, Shagdarsuren E, Bidzhekov K, Meiler et al. (2008):Protective role of CXC receptor 4/CXC ligand 12 unveils the importance of neutrophils in atherosclerosis. Circ Res.; 102(2):209-17.

79-Robbins CS, Chudnovskiy A, Rauch PJ, et al. (2012): Ly-6C(high) monocytes that infiltrate atherosclerotic lesions.Circulation. Jan 17,2012; 125(2):364-74.

80-Konstantin A. Krychtiuk, Stefan P. et al., (2015): Monocyte subset distribution in patients with stable atherosclerosis and elevated levels of lipoprotein(a July-August, Volume 9, Issue4, Pages 533541.

81-Mohammed Shamim Rahman, Andrew J. Murphy \& Kevin J. Woollard (2017): Effects of dyslipidaemia on monocyte production and function in cardiovascular disease. Nature Reviews Cardiology .2017;14,387.400.

82-Timmerman KL, Flynn MG, Coen PM, Markofski MM, Pence BD(2008): Exercise training-induced lowering of inflammatory (CD14+CD16+) monocytes: a role in the antiinflammatory influence of exercise?J Leukoc Biol. ; 84(5): 1271-8.
83-Koichi Node, Ryoma Michishita, Toshiyuki Tsuruta, Naoko Shono, Teruo Inoue, (2010): Effect of Exercise Therapy on Monocyte and Neutrophil Counts in Overweight Women ; 339(2): 152-156.

84-Mendham, C.E. Donges, E.A. Liberts, et al. (2011): Effects of mode and intensity on the acute exercise-induced IL-6 and CRP responses in a sedentary, overweight population Eur. J. Appl. Physiol; 111:1035-1045.

85-Martín-Cordero, J.J. García, M.D. Hinchado, et al. (2011): The interleukin-6 and noradrenaline mediated inflammation stress feedback mechanism is dysregulated in metabolic syndrome: effect of exercise Cardiovasc. Diabetol.; (10) 42.

86-Amano SU, Cohen JL, Vangala $P$, Tencerova M, Nicoloro SM, Yawe JC et al., (2014): Local proliferation of macrophages contributes to obesity-associated adipose tissue inflammation. Cell Metab; 19: 162-171

87-Kablak-Ziembicka A, Przewlocki T, Pieniazek P, Musialek P, Sokolowski A, Drwila R, et al. (2010): The role of carotid intima-media thickens assessment in cardiovascular risk evaluation in patients with poly vascular atherosclerosis, Atherosclerosis $209: 12530$. 